\title{
Research on Fluid Viscous Damper Parameters of Cable-Stayed Bridge in Northwest China
}

\author{
Xiongjun He, Yongchao Yang, Xiang Xiao, and Yulin Deng \\ School of Transportation, Wuhan University of Technology, Wuhan, Hubei 430063, China \\ Correspondence should be addressed to Xiang Xiao; xxdocwhut@163.com
}

Received 16 June 2017; Accepted 22 August 2017; Published 28 September 2017

Academic Editor: Michele Palermo

Copyright (C) 2017 Xiongjun He et al. This is an open access article distributed under the Creative Commons Attribution License, which permits unrestricted use, distribution, and reproduction in any medium, provided the original work is properly cited.

\begin{abstract}
To optimize the aseismic performance of nonlinear fluid viscous dampers (FVD) of cable-stayed bridge in the highly seismic zone, Xigu Yellow River Bridge in northwest China is taken as an example. Nonlinear time-history analysis method is used to research on the relation among the internal forces, displacements, and damping parameters of the 650 tonnage FVD. The method of getting the minimum of binary functions is used to obtain the optimal parameters of FVD. Also, the 1:1 full-scale FVD model is made and used in the constitutive relation test. Then the test result of the damping parameters can be got by normal equation method. The optimized method to obtain the damping parameters is further verified. The results indicate that seismic response in key positions of the cable-stayed bridge can be reduced by installing longitudinal nonlinear FVD between the towers and girders if choosing reasonable damping parameters $C$ and $\xi$. The optimal damping parameters can be calculated accurately by the proposed method of optimizing damping parameters of nonlinear FVD, and the constitutive relation test verifies the correctness of the optimization analysis method. Conclusions concerned can be applied to the design of nonlinear FVD for cable-stayed bridges.
\end{abstract}

\section{Introduction}

For cable-stayed bridges, under longitudinal earthquake input, different tower-girder connection forms will have significant influence on the internal force response of main towers and its foundations, also on the displacements of girder end, and on the relative displacements of the girder and the approach bridge $[1,2]$. The problem that the bridge tower internal force will be greatly increased in consolidated system and the problem that the longitudinal displacements of the girder end and the tower top will be enlarged in longitudinal floating system can be overcome by the damping system installed between the towers and girders $[3,4]$. Therefore, increasing numbers of dampers are favored and used in aseismic system for cable-stayed bridges. However, the aseismic performances of the damper are mainly determined by the designed values of damping parameters $C$ and $\xi$.

At present, there are few references about the parameter selection of fluid viscous dampers (FVD) in cable-stayed bridges. Researches have shown that choosing the reasonable damping parameters of FVD can reduce the seismic response of key positions of cable-stayed bridges [5-7]. But the references about the selection of damping parameters mainly rely on subjective experience, which lacks experiment basis for selecting damping parameters $[8,9]$. Therefore, the method, based on the constitutive relation test upon the FVD model, which is used to get the optimal value of the damping parameters of nonlinear FVD [10,11], turns out to be useful for the design of FVD in cable-stayed bridges.

To improve the aseismic performance of the cable-stayed bridge, this paper presents a versatile procedure for the design of nonlinear FVD in cable-stayed bridges. Firstly, the relation among the internal forces, displacements, and damping parameters of the FVD under the action of earthquake is studied. The method of getting the minimum of binary functions is used to obtain the optimal parameters of FVD. Secondly, the results of the methodology adopted to obtain the optimized damping parameters have been confirmed by a constitutive relation test conducted on a full-scale model of the FVD. Seismic response in key positions of the cable-stayed bridge can be reduced by installing longitudinal nonlinear FVD if choosing reasonable damping parameters. 


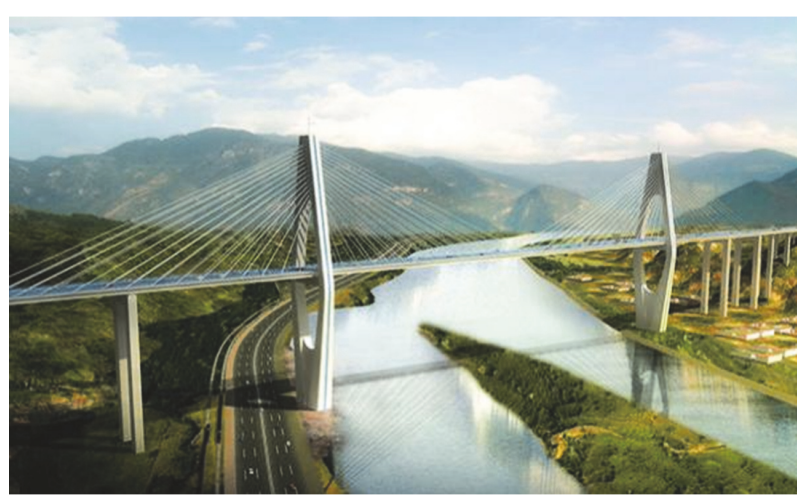

Figure 1: Xigu Yellow River Bridge.

\section{Project Overview}

Xigu Yellow River Bridge in northwest China, a key project in Lianhuo national trunk line of expressway, is a cablestayed bridge with the longest span and the tallest tower over Yellow River in northwest China. As is shown in Figure 1, the main bridge is a cable-stayed bridge with double tower, double cable plane, and steel-concrete composite beam, of which the span is $(67+110+360+110+67) \mathrm{m}$. Four 650 tonnage dampers are installed between the towers and girders. Reinforced concrete rhombus tower is used and the south tower is 151 meters and the north tower is 147 meters. Steel I-beam and concrete composite girders are used in the main beam, and the composite girder is 2.83 meters high in the center of the steel girder and 3.06 meters in the center of the bridge. Low relaxed galvanized parallel steel tendon, with the $7 \mathrm{~mm}$ diameter and tensile strength not less than $1,770 \mathrm{MPa}$, is used in the stay cables and the longest cable is 187.068 meters weighing 17 tons. The seismic peak acceleration is $0.2 \mathrm{~g}$ and the predominant period of seismic response spectrum is $0.40 \mathrm{~s}$ in the bridge site, which is in eight-degree earthquake zone.

Based on the design and construction data, three-dimension element method is used to establish the finite element analytical model $[12,13]$ of Xigu Yellow River Bridge (Figure 2), in which the single girder mechanical model is utilized in the girder. Tension-only spatial truss element is used in stay cables and Ernst formula is utilized to rectify the elasticity modulus of the cables to verify the sagging effect $[14,15]$. Spatial girder element is utilized to simulate the girders, the towers, and the piers. Damper element is used to simulate FVD $[16,17]$. At the same time, the dead load effect on the structural stiffness is taken into consideration. The masterslave relation is used to simulate the girder joints, the lifting points of the stay cables, and the anchorage zone of the stay cables $[18,19]$. The $6 \times 6$ coupled spring is adopted to simulate the mutual effect between the pile and soil in both pile foundations of the towers and the piers. The acceleration time-history curve with exceeding probability to be 10 percent in the future 50 years, which is provided from seismological bureau of Gansu Province, is taken as the earthquake load for Xigu Yellow River Bridge [20, 21].

\section{Parameter Analysis of Nonlinear FVD}

FVD consist of (Figure 3) cylinder, piston, hydraulic valve, piston rod, and silicone oil [22]. Under the earthquake load, the movement of the structure pushes the piston and the cylinder to produce relative displacement, and the reciprocating motion of the piston drives the flow of silicone oil. The friction between the molecules and that between the surface of the cylinder and the fluid generates heat so that the seismic energy can be converted into heat energy and the damping effect can be realized [23, 24]. FVD are common shock absorbers in bridge engineering, and the fundamental principle of damping property is [25-28]

$$
F=C V^{\xi}
$$

where $F$ is the damping force, $C$ is the damping coefficient, $V$ is the relative velocity of dampers, and $\xi$ is the velocity index. In particular, when the velocity index is equal to 1 , the damping force is proportional to the relative velocity and the damper turns out to be a linear one.

As can be seen from (1), the response of the damper to the structure is different because of the different damping parameters of FVD. However, most of researches mainly rely on subjective experience to select damping parameters and lack a unified method to select the parameters quantitatively [29-32]. Therefore, it is necessary to do sensitivity analysis of damping parameters $C$ and $\xi$ to discuss the variation of the structural response with the change of parameters, which is useful for the parameter design of the FVD.

In bridge engineering, the value of velocity index $\xi$ is usually in the range of $0.2 \sim 2.0$, and the damping coefficient $C$ is usually in the range of $1000 \sim 20000 \mathrm{kN} \times(\mathrm{s} / \mathrm{m})^{\xi}$. Considering the FVD of Xigu Yellow River Bridge and the finite element analysis model, the damping coefficient $C$ is set as $5000,7500,10000,15000$, and $20000 \mathrm{kN} \times(\mathrm{s} / \mathrm{m})^{\xi}$, respectively, and the velocity index $\xi$ is set as $0.2,0.3,0.4,0.5,0.6$, and 0.7 , respectively. According to the trend of the calculation results of controlled internal force in the south tower bottom, it is easier to obtain the appropriate damping parameters when $C$ is set as $2500,5000,7500,10000$, and $15000 \mathrm{kN} \times(\mathrm{s} / \mathrm{m})^{\xi}$, respectively. So there are a total of 30 conditions for parameter analysis.

3.1. Parameter Analysis of Controlled Internal Force. Because the cable-stayed bridge is a symmetrical structure, the south tower is taken as an example. The finite element model shown in Figure 2 is used to do parameter analysis in the 30 working conditions. The actions applied to the bridge include only earthquake acceleration at the bottom of each pier, which are provided from seismological bureau of Gansu Province of China and have $2 \%$ of exceeding probability of 50 years. Nonlinear time-history analysis method is used to research on the relation among the internal forces, displacements, and damping parameters.

As is shown in Figure 4, because of different damping coefficient $C$, the numerical values of longitudinal shear force in the tower bottom will change with velocity index $\xi$. And it is not hard to figure out that when the damping 


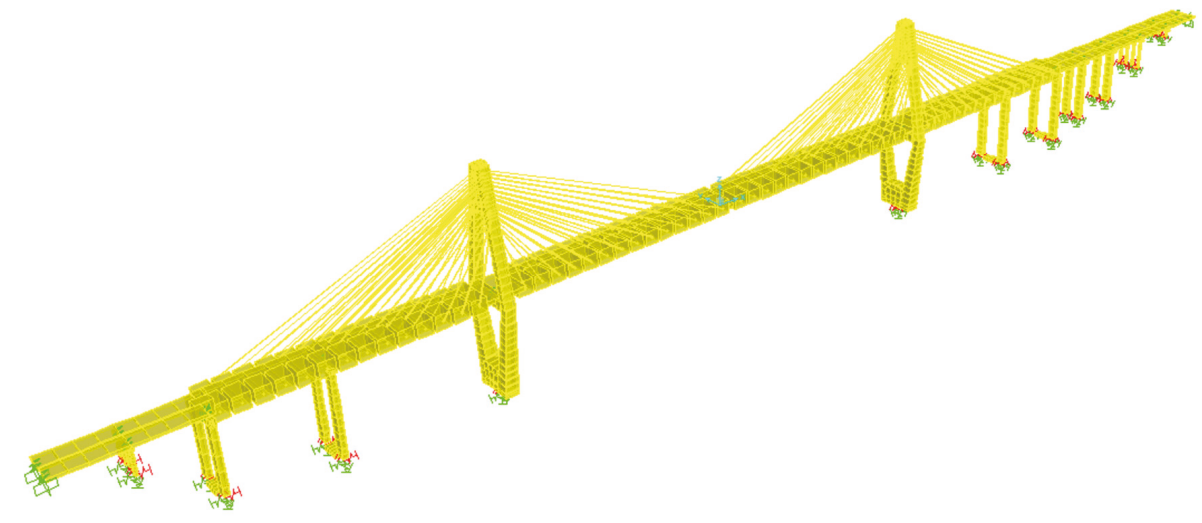

FIgURE 2: Finite element model of Xigu Yellow River Bridge.



Figure 3: The fluid viscous damper.

coefficient $C$ is in the range of 5,000 10,000 $\mathrm{kN} \times(\mathrm{s} / \mathrm{m})^{\xi}$ and the velocity index $\xi$ is in the range of $0.4 \sim 0.7$, the seismic shear force in tower bottom is at a low level. Similarly, because of different damping coefficient $C$, the bending moment in tower bottom will change with velocity index $\xi$. And it is easy to find that when the damping coefficient $C$ is in the range of 7,500 10,000 $\mathrm{kN} \times(\mathrm{s} / \mathrm{m})^{\xi}$ and the velocity index $\xi$ is in the range of $0.4 \sim 0.5$ or when damping coefficient $C$ is equal to $15,000 \mathrm{kN} \times(\mathrm{s} / \mathrm{m})^{\xi}$ and velocity index $\xi$ is equal to 0.7 , the bending moment in tower bottom is at a low level. Therefore, from the perspective of reducing the seismic response in tower bottom, the optimal effect can be achieved when damping coefficient $C$ is in the range of $7,500 \sim 10,000 \mathrm{kN} \times(\mathrm{s} / \mathrm{m})^{\xi}$ and velocity index $\xi$ is in the range of $0.4 \sim 0.5$.

As is shown in Figure 5, for the foundation shear force, when damping coefficient $C$ is less than $10,000 \mathrm{kN} \times(\mathrm{s} / \mathrm{m})^{\xi}$, the foundation shear force response decreases with $\xi$ decreasing, and when damping coefficient $C$ is greater than 10,000 , the foundation shear force response decreases first and then increases with $\xi$ increasing. As for foundation bending moment, with the increase of $C$ and the decrease of $\xi$, the foundation bending moment response gets smaller and smaller. Therefore, from the perspective of reducing the internal force in tower bottom foundation, the optimal effect can be achieved when damping coefficient $C$ is in the range of 7,500 15,000 $\mathrm{kN} \times(\mathrm{s} / \mathrm{m})^{\xi}$ and damping constant $\xi$ is in the range of $0.3 \sim 0.5$.
3.2. Parameter Analysis of Controlled Displacement. As is shown in Figure 6(a), the girder end displacements decrease with the increase of damping coefficient $C$. When damping coefficient $C$ is greater than 10,000 , the influence of $C$ on the girder end displacement is weakened, and the increase of $\xi$ has little influence on the girder end displacements. Therefore, from the perspective of reducing the girder end displacements, the optimal effect can be reached when damping coefficient $C$ is in the range of $10,000 \sim 20,000 \mathrm{kN} \times(\mathrm{s} / \mathrm{m})^{\xi}$ and velocity index $\xi$ is in the range of $0.3 \sim 0.5$.

As is shown in Figure 6(b), when damping coefficient $C$ is less than $10,000 \mathrm{kN} \times(\mathrm{s} / \mathrm{m})^{\xi}$, the relative displacements between the south main bridge and the approach bridge increase with $\xi$ increasing, but when damping coefficient $C$ is greater than $10,000 \mathrm{kN} \times(\mathrm{s} / \mathrm{m})^{\xi}$, the relative displacements decrease first and then increase with $\xi$ increasing. However, from the perspective of reducing the displacements, the optimal effect can be achieved when damping coefficient $C$ is in the range of 10,000 20,000 $\mathrm{kN} \times(\mathrm{s} / \mathrm{m})^{\xi}$ and velocity index $\xi$ is in the range of $0.3 \sim 0.5$.

Based on the above analysis, the seismic response in the tower bottom, the tower foundation, and the girder can be reduced effectively by installing longitudinal nonlinear FVD between the towers and girders when the velocity index $\xi$ is in the range of $0.4 \sim 0.5$ and the damping coefficient $C$ is about $10,000 \mathrm{kN} \times(\mathrm{s} / \mathrm{m})^{\xi}$.

3.3. Optimization of Damping Parameters. As is shown in Sections 3.1 and 3.2, the damping parameters of the FVD can be preliminarily determined qualitatively by simulating and analyzing the finite element model in multiple conditions. However, when determining the optimal damping parameter in many researches [33-36], the results of multiple situations are simply put to take the common intersection. This method lacks quantitative analysis of multiple conditions. It is obvious that the internal forces or displacements of key positions are binary function of damping parameters $C$ and $\xi$. Thus, least square method can be used to perform the surface fitting of the relation among the internal forces or the displacements of key positions with damping parameters $C$ and $\xi$. And then the problem is transformed to solve the extreme values of 


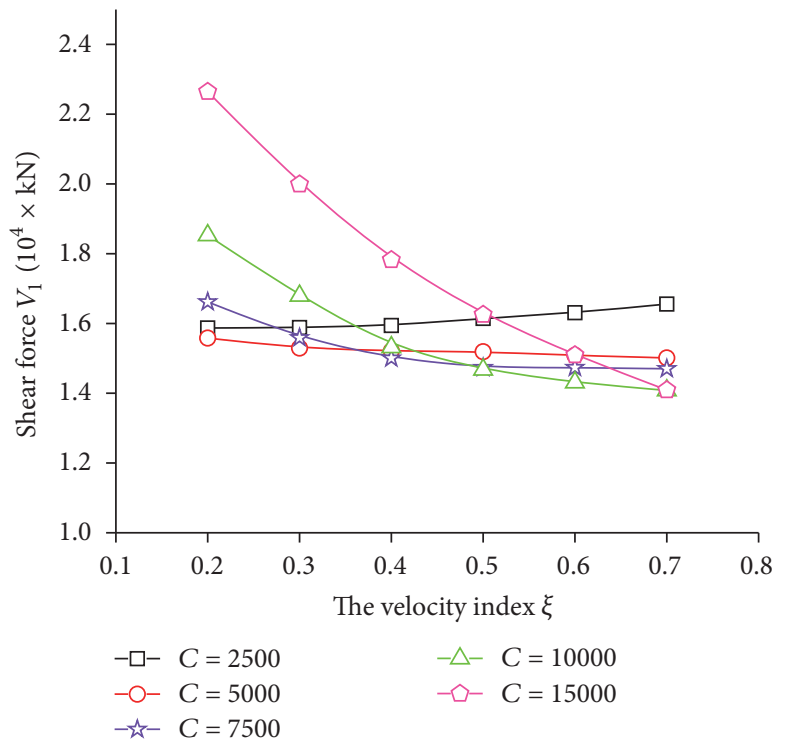

(a) Longitudinal shear force in tower bottom

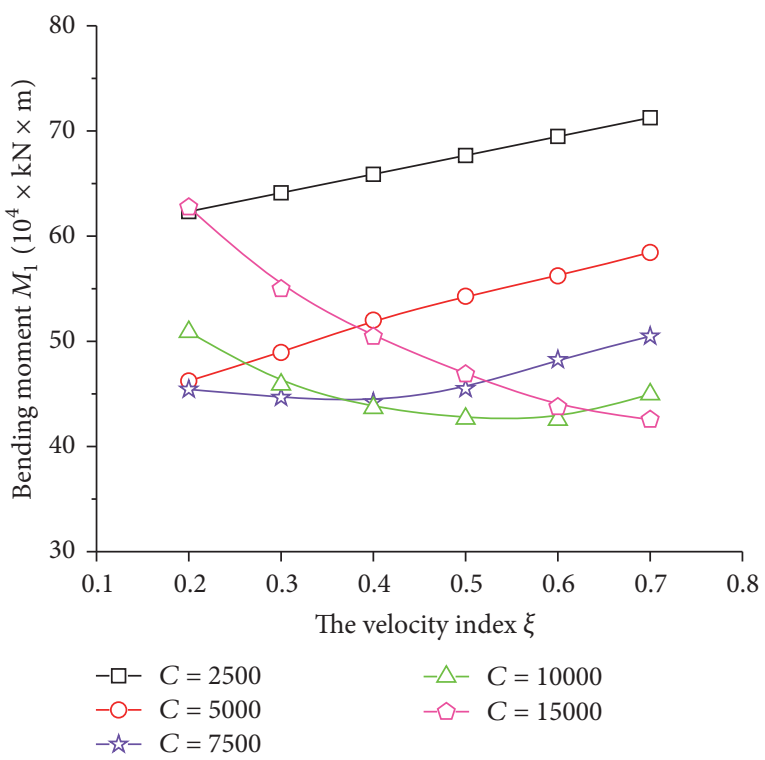

(b) Longitudinal bending moment in tower bottom

FIgURE 4: Change of controlled internal force in the south tower bottom with damping parameters.

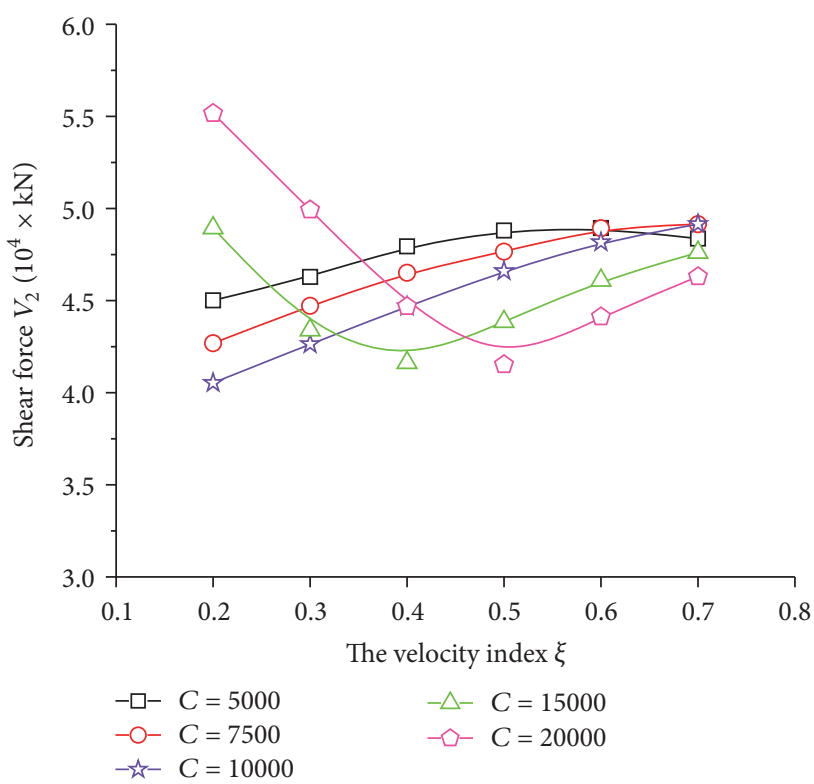

(a) Longitudinal shear force in south tower foundation

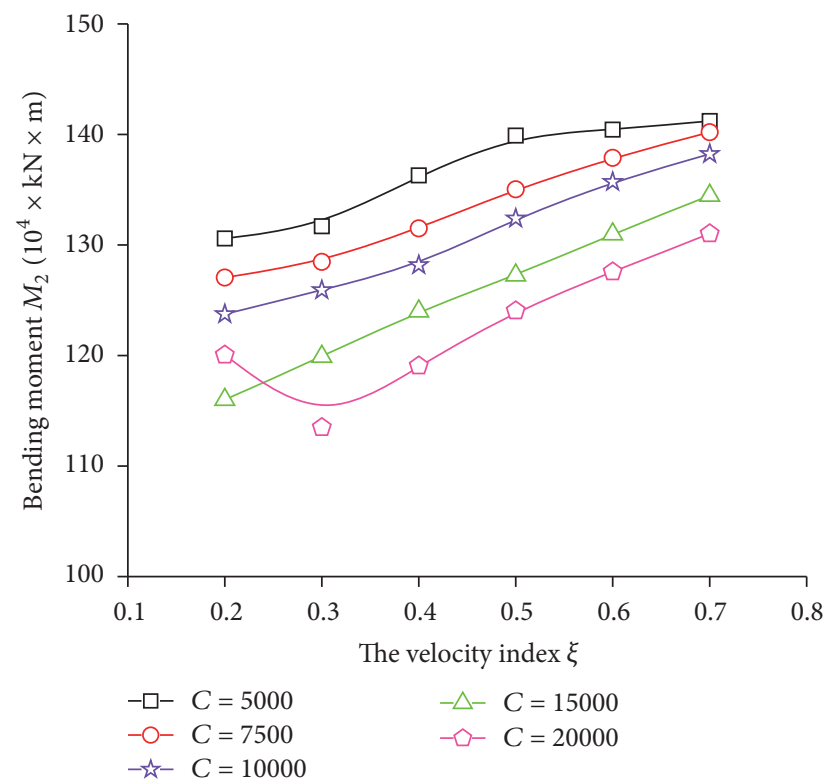

(b) Longitudinal bending moment in south tower foundation

FIGURE 5: Change of controlled internal force in the south tower foundation with damping parameters.

the nonlinear binary function. The least squares fitting is realized by the LSQCURVEFIT command in MATLAB, and the surface fitting results are as Table 1.

The coefficient of determination $r^{2}$ is

$$
r^{2}=\frac{\sum_{i=1}^{n}\left(\hat{y}_{i}-\bar{y}\right)^{2}}{\sum_{i=1}^{n}\left(y_{i}-\bar{y}\right)^{2}},
$$

where $n$ is the sample number, $\hat{y}_{i}$ is the corresponding value of regression equation, $\bar{y}$ is the sample average, and $y_{i}$ is the sample corresponding value. The coefficient of determination $r^{2}$ reflects the goodness of fitting, and its range is $[0,1]$. The closer the $r^{2}$ is to 1 , the better the regression equation is fitted.

To obtain the optimal damping parameters, the results of surface fitting in Table 1 are arranged:

$$
\begin{aligned}
& V=V_{1}+V_{2}, \\
& M=M_{1}+M_{2}, \\
& D=D_{1}+D_{2} .
\end{aligned}
$$


TABLE 1: Parametric regression analysis.

Surface fitting results

Coefficient of

Shear force in south tower bottom: $V_{1}=\left(18205-0.697 C+80010 \xi+1.373 \times 10^{-4} C+15187 \xi^{2}-7.886 C \cdot \xi\right) /(1+$ determination $r^{2}$

$\left.5.199 \xi-3.245 \times 10^{-4} \mathrm{C} \cdot \xi\right)$

0.995

Bending moment in south tower bottom: $M_{1}=\left(896827-154.105 C+3155531 \xi+1.376 \times 10^{-2} C^{2}+\right.$

$\left.1061168 \xi^{2}-239.911 C \cdot \xi\right) /(1+4.339 \xi)$

Shear force in south tower foundation: $V_{2}=\left(44375-3.07 C-268759 \xi-6.29 \times 10^{-5} C^{2}-25432 \xi^{2}+\right.$

$19.88 C \cdot \xi) /\left(1-8.06 \times 10^{-5} C-5.75 \xi+3.87 \times 10^{-4} C \cdot \xi\right)$

0.991

Bending moment in south tower foundation: $M_{2}=1345037-18.064 C+216122 \xi+7.956 C \cdot \xi$

Displacement in girder south end: $D_{1}=\left(0.18-2.19 \times 10^{-5} C-0.19 \xi+1.88 \times 10^{-10} C^{2}+0.36 \xi^{2}+\right.$

$\left.5.05 \times 10^{-5} \mathrm{C} \cdot \xi\right) /\left(1-1.27 \times 10^{-4} \mathrm{C}-1.38 \xi+4.25 \times 10^{-4} \mathrm{C} \cdot \xi\right)$

0.962

0.951

Relative displacement between the main bridge and the approach bridge: $D_{2}=0.239-1.448 \times 10^{-5} C+0.161 \xi+$ $1.014 \times 10^{-9} C^{2}+0.193 \xi^{2}-2.70 \times 10^{-5} C \cdot \xi$

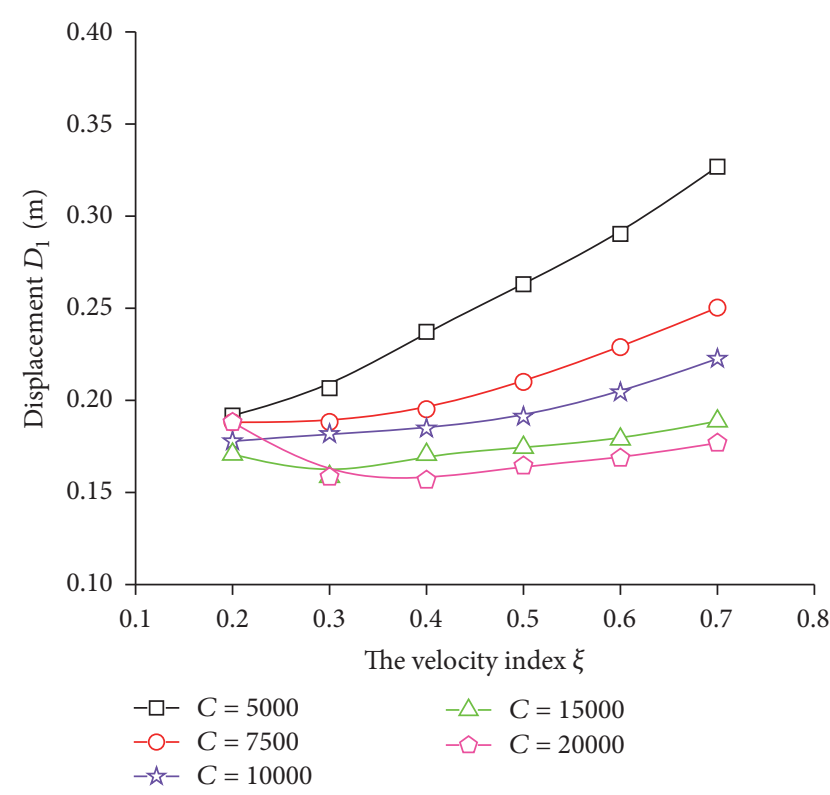

(a) Displacements in the girder south end

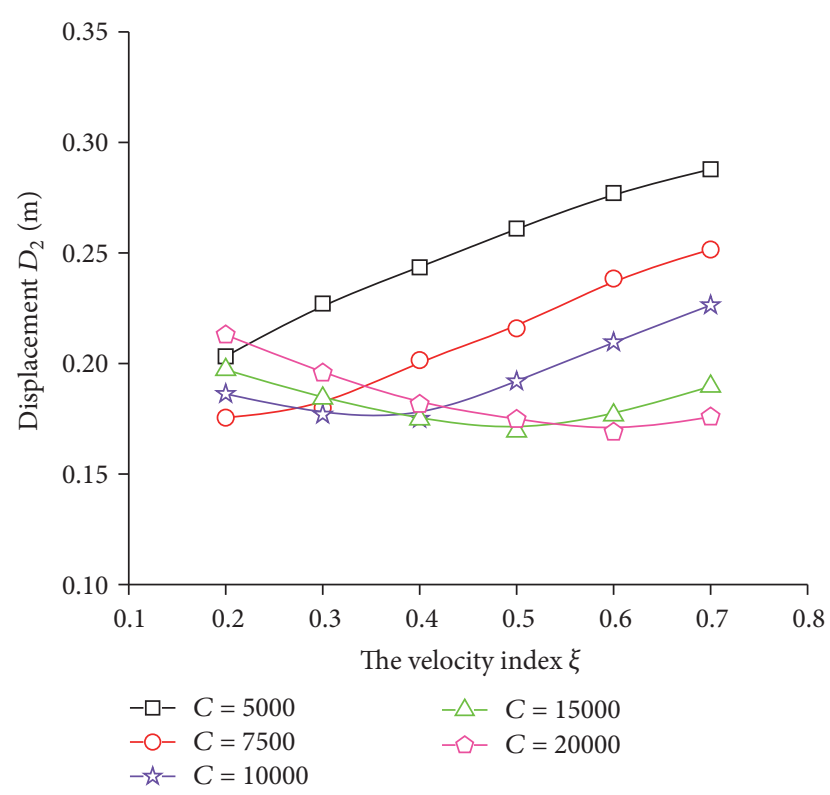

(b) Relative displacements between the south main bridge and the approach bridge

FIGURE 6: Change of controlled displacements with damping parameters.

The constraint condition is as follows: $C \in[2000,20000]$ and $\xi \in[0.2,0.7]$. The damping parameters $C$ and $\xi$ can be got as long as the minimal values of (2) with constraint condition are solved. Take the average value of the three sets of damping parameters as the optimal damping parameters: $C=10871 \mathrm{kN} \times(\mathrm{s} / \mathrm{m})^{\xi}$ and $\xi=0.415$. The above-mentioned method can be applied to obtain the optimal damping parameters when to design the nonlinear FVD in bridges.

\section{Model Making and Experiment}

To further verify the optimization method of damping parameters in Section 3.3, in laboratory for training and research in earthquake engineering and seismology at EUCENTRE (Pavia, Italy), the damper tester showed in Figure 7 is applied to do the constitutive relation test on the 1:1 full-scale damper model of Xigu Yellow River Bridge in
TABLE 2: Main parameters of the FVD model.

\begin{tabular}{lccc}
\hline $\begin{array}{l}\text { Maximum } \\
\text { damping force }\end{array}$ & $\begin{array}{c}\text { Length of } \\
\text { FVD model }\end{array}$ & $\begin{array}{c}\text { Maximum } \\
\text { displacement }\end{array}$ & $\begin{array}{c}\text { Maximum } \\
\text { velocity }\end{array}$ \\
\hline $6500 \mathrm{kN}$ & $3457 \mathrm{~mm}$ & $\pm 400 \mathrm{~mm}$ & $340.6 \mathrm{~mm} / \mathrm{s}$ \\
\hline
\end{tabular}

Lanzhou. The installation for testing is shown in Figure 8, and the main parameters of the damper model are shown in Table 2.

Make the damper tester control the piston rod to move at the speed of $3 \mathrm{~mm} / \mathrm{s}, 30 \mathrm{~mm} / \mathrm{s}, 60 \mathrm{~mm} / \mathrm{s}$, and $80 \mathrm{~mm} / \mathrm{s}$ successively so that the constitutive relation test can be conducted. Then the relation between the damping force and the relative movement velocity of the piston pod can be tested. Conduct 3 complete axial displacement cyclic loadings in each set. Namely, the displacement is controlled from 0 to the 




Figure 7: The damper tester.

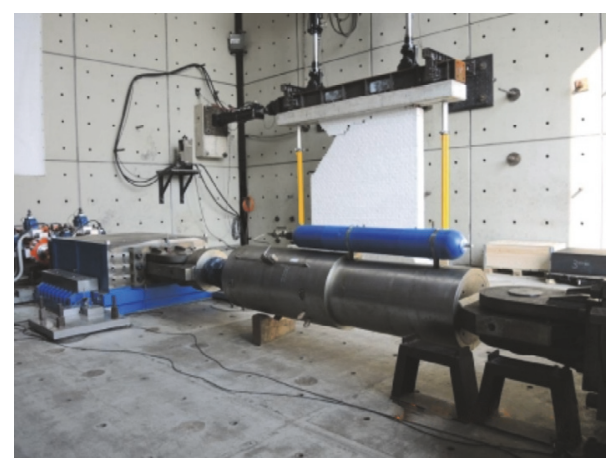

FIGURE 8: Installation for testing.

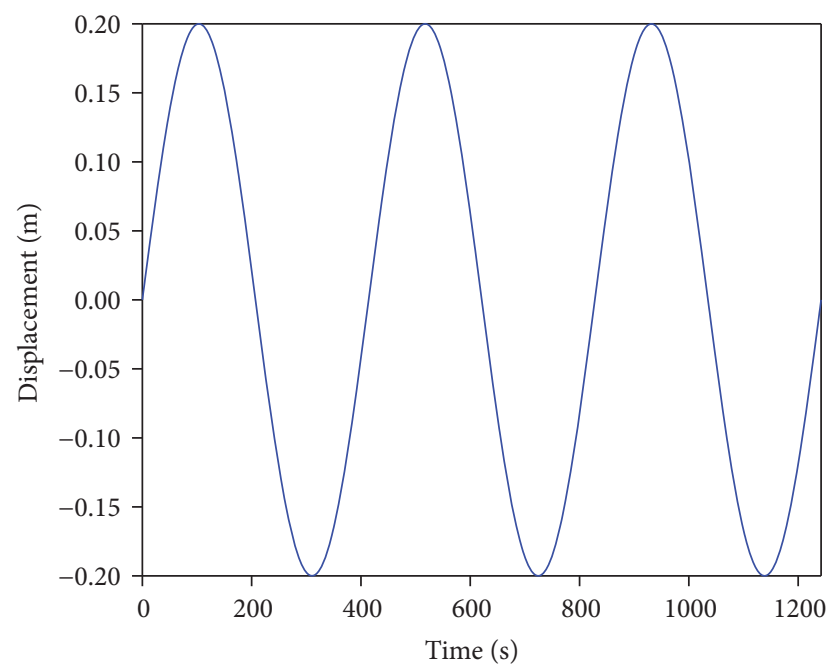

FIGURE 9: Displacement time-history curve of the damper piston pod.

half of the positive maximum range and then to the half of the negative maximum range, and back to 0 at last. In the first set of test, the relative displacement of the controlled piston pod is shown in Figure 9, and the time-history curve of the FVD relative velocity is shown in Figure 10, and the time-history curve of the damping force is shown in Figure 11.

As is shown from the test results in Figures 10 and 11, when the relative displacement of the damper piston pod is

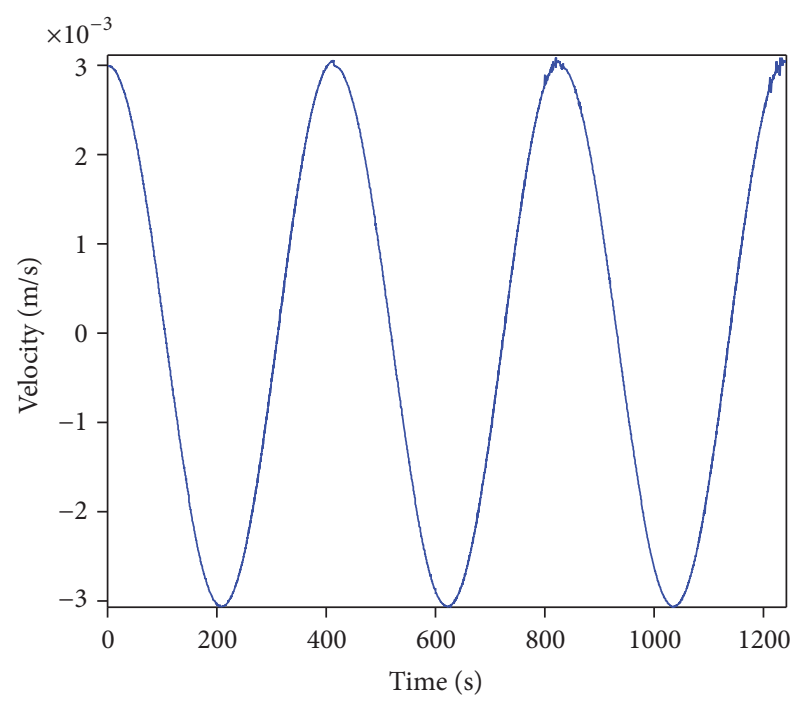

FIGURE 10: Velocity time-history curve of the damper piston pod.

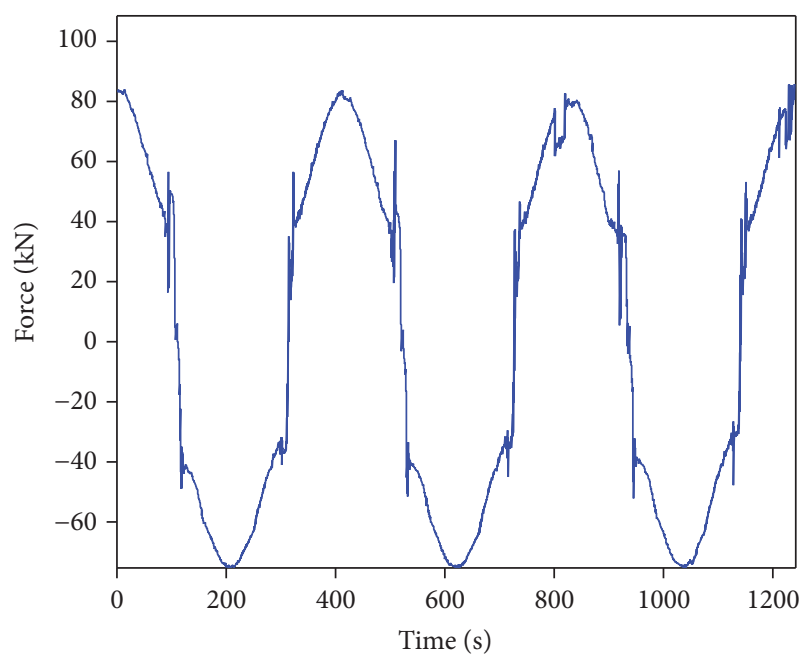

FIgURE 11: Time-history curve of the damping force.

a sine curve, the time-history curve of the velocity and the time-history curve of the damping force can be seen as cosine curve approximately. And the damping force changes greatly when the velocity of the damper is close to 0 .

The damping forces of the FVD in four sets tests with the relative velocities are shown in Figure 12. Obviously, the test value curve of the damping force is consistent with the theoretical value curve. Applying a logarithmic law at each member of (1), the following expression is obtained:

$$
\log F=\log C+\xi \log V
$$

When the damping force $F$ and velocity $V$ are already known, (4) represents a linear problem in the parameters 


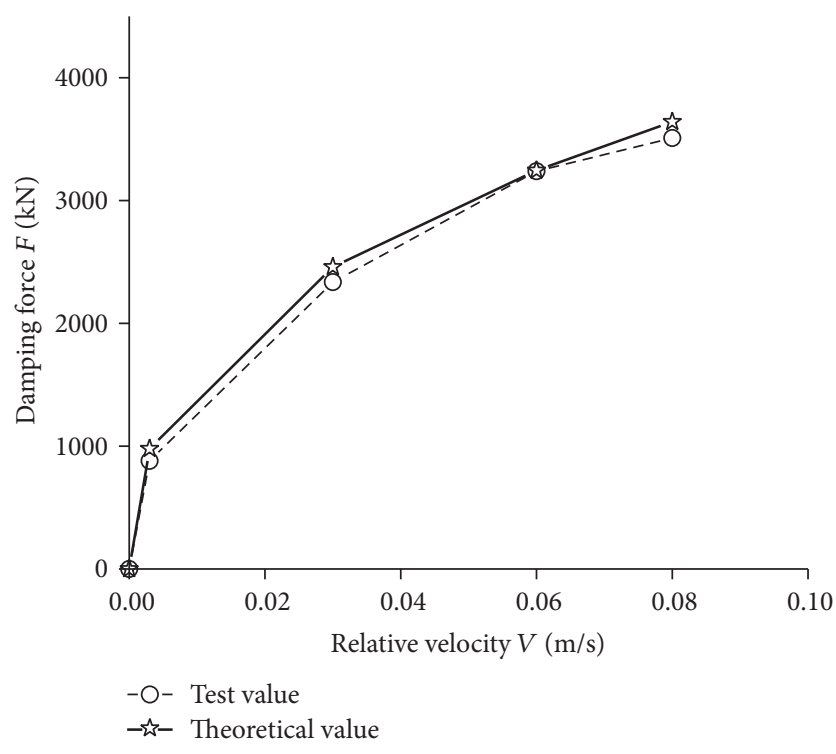

FIGURE 12: Damping force changes with the velocity.

$\log C$ and $\xi$. To solve the least squares problem, the normal equations method can be used.

$$
\begin{aligned}
& {\left[\begin{array}{c}
\log F_{1} \\
\log F_{2} \\
\vdots \\
\log F_{n}
\end{array}\right]=\left[\begin{array}{cc}
1 & \log V_{1} \\
1 & \log V_{2} \\
\vdots & \vdots \\
1 & \log V_{n}
\end{array}\right] \cdot\left[\begin{array}{c}
\log C \\
\xi
\end{array}\right] \Longrightarrow } \\
& \vec{F}=\vec{V} \cdot\left[\begin{array}{c}
\log C \\
\xi
\end{array}\right] .
\end{aligned}
$$

So the value of $\log C$ and $\xi$ can be calculated with

$$
\left[\begin{array}{c}
\log C \\
\xi
\end{array}\right]=\left[\vec{V}^{\mathrm{T}} \cdot \vec{V}\right]^{-1} \cdot \vec{V}^{\mathrm{T}} \cdot \vec{F}
$$

Substituting the damping forces and velocities tested in the four sets of tests into (6), the damping parameters $C=$ $10496 \mathrm{kN} \times(\mathrm{s} / \mathrm{m})^{\xi}$ and $\xi=0.427$ can be got. The damping parameters of the test are consistent with that of the optimal method, which further verifies the method of optimizing damping parameters.

\section{Conclusion}

Taking Xigu Yellow River Bridge in Lanzhou where the seismic intensity is eight degrees as an example, the method of combining finite element simulation and the $1: 1$ full-scale FVD model test is adopted to discuss the reasonable FVD parameters of a cable-stayed bridge in highly seismic zone. The following conclusions can be reached:

(1) The FVD are longitudinally installed between the towers and girders in cable-stayed bridge, whose damping parameters have great significance on the seismic response.
After the simulation analysis in 30 conditions by using the finite element software, the reasonable damping parameters can be preliminarily determined. For the nonlinear FVD of Xigu Yellow River Bridge, the seismic response in the tower bottom, tower foundation, and the girder can be effectively reduced when the velocity index $\xi$ is in the range of $0.4 \sim 0.5$ and the damping coefficient $C$ is about $10000 \mathrm{kN} \times(\mathrm{s} / \mathrm{m})^{\xi}$.

(2) When nonlinear FVD are used in the design of bridges, least square method can be applied to conduct the surface fitting on the relation among the internal forces, displacements, and damping parameters $C$ and $\xi$. So the problem is transformed to solve the extreme values of the nonlinear constraint binary function. The optimal values of damping parameters can be got explicitly by the method, which is useful for the design of nonlinear FVD installed in cable-stayed bridges.

(3) Through the constitutive relation test in the 1:1 fullscale FVD model of Xigu Yellow River Bridge in Lanzhou, the results show that when the relative displacement of the damper piston pod is a sine curve, the time-history curve of the velocity and the time-history curve of the damping force can be seen as cosine curve approximately. And the damping force changes greatly when the velocity of the damper is close to 0 .

(4) Through the comparison between the finite element simulation analysis and the full-scale FVD model test, the test value curve of the damping force keeps consistent with the theoretical value curve. The damping parameters $C=$ $10496 \mathrm{kN} \times(\mathrm{s} / \mathrm{m})^{\xi}$ and $\xi=0.427$ are got, which agrees with the result of the finite element analysis. The method of optimizing damping parameters is further verified.

\section{Conflicts of Interest}

The authors declare that there are no conflicts of interest regarding the publication of this paper.

\section{Acknowledgments}

Thanks are due to the Laboratory for Training and Research in Earthquake Engineering and Seismology at EUCENTRE (Pavia, Italy) for assistance with the experiments. The authors would like to express appreciation for the financial support by Project of Science and Technology Research Program of Department of Transport, Gansu Province (GJJS [2016] no. 74).

\section{References}

[1] R. L. Teixeira, F. P. L. Neto, and J. F. Ribeiro, "Modelling and experimental investigation of an active damper," Shock and Vibration, vol. 13, no. 4-5, pp. 343-354, 2006.

[2] Z. Guan, H. You, and J.-Z. Li, "Lateral isolation system of a longspan cable-stayed bridge with heavyweight concrete girder in a high seismic region," Journal of Bridge Engineering, vol. 22, no. 1, Article ID 04016104, 2017.

[3] M. H. Alhamaydeh, S. A. Barakat, and F. H. Abed, "Multiple regression modeling of natural rubber seismic-isolation systems with supplemental viscous damping for near-field ground 
motion," Journal of Civil Engineering and Management, vol. 19, no. 5, pp. 665-682, 2013.

[4] P. P. Diotallevi, L. Landi, and A. Dellavalle, "A methodology for the direct assessment of the damping ratio of structures equipped with nonlinear viscous dampers," Journal of Earthquake Engineering, vol. 16, no. 3, pp. 350-373, 2012.

[5] G. P. Colato, S. Infanti, and M. G. Castellano, "Special fluid viscous dampers for the messina strait bridge," in Proceedings of the 2008 Seismic Engineering International Conference Commemorating the 1908 Messina and Reggio Calabria Earthquake, MERCEA 2008, pp. 1374-1380, ita, July 2008.

[6] M. C. Constantinou and M. D. Symans, Experimental and analytical investigation of seismic response of structures with supplemental fluid viscous dampers, National Center for earthquake engineering research, Buffalo, NY, USA, 1992.

[7] L. Liu, X. Zhang, and Q. Yang, "Estimation of the optimum parameters of fluid viscous dampers for seismic response control of highway bridges," in Proceedings of the 29th Chinese Control Conference, CCC'10, pp. 5705-5711, chn, July 2010.

[8] N. Gluck, A. M. Reinhorn, J. Gluck, and R. Levy, "Design of supplemental dampers for control of structures," Journal of Structural Engineering, vol. 122, no. 12, pp. 1394-1399, 1996.

[9] R. Greco and G. C. Marano, "Identification of parameters of Maxwell and Kelvin-Voigt generalized models for fluid viscous dampers," Journal of Vibration and Control, vol. 21, no. 2, pp. 260-274, 2015.

[10] X. He, W. Chen, and B. Zhu, "Theoretical analysis on the damping characteristics of a clearance type viscous damper," Advanced Science Letters, vol. 15, no. 1, pp. 422-424, 2012.

[11] K. Ikago, K. Saito, and N. Inoue, "Seismic control of singledegree-of-freedom structure using tuned viscous mass damper," Earthquake Engineering \& Structural Dynamics, vol. 41, no. 3, pp. 453-474, 2012.

[12] N. Makris, M. C. Constantinou, and G. F. Dargush, "Analytical model of viscoelastic fluid dampers," Journal of Structural Engineering, vol. 119, no. 11, pp. 3310-3325, 1993.

[13] T. T. Soong and G. F. Dargush, Passive Energy Dissipation Systems in Structural Engineering, John Wiley \& Sons, Chichester, UK, 1997.

[14] Q. Wu, J. Dai, and H. Zhu, "Optimum design of passive control devices for reducing the seismic response of twin-towerconnected structures," Journal of Earthquake Engineering, pp. 135, 2017.

[15] G.-H. Zhao and Y.-M. Zhang, "Parametric sensitivity study on fluid viscous damper of long span suspension bridge," Advanced Materials Research, vol. 255-260, pp. 998-1002, 2011.

[16] T. J. Sullivan and A. Lago, “Towards a simplified Direct DBD procedure for the seismic design of moment resisting frames with viscous dampers," Engineering Structures, vol. 35, pp. 140148, 2012.

[17] T. S. Vader and C. C. McDaniel, "Influence of dampers on seismic response of cable-supported bridge towers," Journal of Bridge Engineering, vol. 12, no. 3, pp. 373-379, 2007.

[18] L. Landi, P. P. Diotallevi, and G. Castellari, "On the design of viscous dampers for the rehabilitation of plan-asymmetric buildings," Journal of Earthquake Engineering, vol. 17, no. 8, pp. 1141-1161, 2013.

[19] B. B. Soneji and R. S. Jangid, "Influence of soil-structure interaction on the response of seismically isolated cable-stayed bridge," Soil Dynamics and Earthquake Engineering, vol. 28, no. 4, pp. 245-257, 2008.
[20] S. Silvestri and T. Trombetti, "Physical and numerical approaches for the optimal insertion of seismic viscous dampers in sheartype structures," Journal of Earthquake Engineering, vol. 11, no. 5, pp. 787-828, 2007.

[21] M. S. A. Khan, A. Suresh, and N. S. Ramaiah, "Numerical study of magnetic circuit response in magneto-rheological damper," Journal of Engineering, Design and Technology, vol. 14, no. 1, pp. 196-210, 2016.

[22] P. P. Diotallevi, L. Landi, and S. Lucchi, "Seismic retrofit of existing buildings with viscous dampers: a direct procedure for the determination of the required supplemental damping," in Proceedings of the 7th International Structural Engineering and Construction Conference: New Developments in Structural Engineering and Construction, ISEC 2013, pp. 1761-1766, Honolulu, Hawaii, USA, June 2013.

[23] J. J. Aguirre, J. L. Almazán, and C. J. Paul, "Optimal control of linear and nonlinear asymmetric structures by means of passive energy dampers," Earthquake Engineering and Structural Dynamics, vol. 42, no. 3, pp. 377-395, 2013.

[24] J. Jia and H. Hua, "Test verification of a design method for a fluid viscous damper," Advanced Materials Research, vol. 291-294, pp. 2085-2088, 2011.

[25] M. D. Martínez-Rodrigo, J. Lavado, and P. Museros, "Dynamic performance of existing high-speed railway bridges under resonant conditions retrofitted with fluid viscous dampers," Engineering Structures, vol. 32, no. 3, pp. 808-828, 2010.

[26] S. Silvestri, G. Gasparini, and T. Trombetti, "A five-step procedure for the dimensioning of viscous dampers to be inserted in building structures," Journal of Earthquake Engineering, vol. 14, no. 3, pp. 417-447, 2010.

[27] D. Konstantinidis, J. M. Kelly, and N. Makris, In-Situ Monitoring of The Force Output of Fluid Dampers: Experimental Investigation, Pacific Earthquake Engineering Research Center, 2011.

[28] L. Landi, P. P. Diotallevi, and G. Castellari, "Design of viscous dampers for the seismic retrofit of plan-asymmetric structures," in The Seventh International Structural Engineering and Construction Conference (ISEC-7), pp. 18-23, Honolulu, Hawaii, USA, 2013.

[29] L. Landi and P. P. Diotallevi, "Design procedure for the seismic retrofit of existing RC buildings with viscous dampers: a case study," in World Congress on Advances in Structural Engineering and Mechanics (ASEM+), pp. 3673-3690, Seoul, Korea, 2011.

[30] D. I. Narkhede and R. Sinha, "Behavior of nonlinear fluid viscous dampers for control of shock vibrations," Journal of Sound and Vibration, vol. 333, no. 1, pp. 80-98, 2014.

[31] F. Sadek, B. Mohraz, and M. A. Riley, "Linear procedures for structures with velocity-dependent dampers," Journal of structural engineering New York, N.Y., vol. 126, no. 8, pp. 887$895,2000$.

[32] C. J. Black and N. Makris, "Viscous heating of fluid dampers under small and large amplitude motions: experimental studies and parametric modeling," Journal of Engineering Mechanics, vol. 133, no. 5, pp. 566-577, 2007.

[33] J. Zhu, W. Zhang, K. F. Zheng, and H. G. Li, "Seismic design of a long-span cable-stayed bridge with fluid viscous dampers," Practice Periodical on Structural Design and Construction, vol. 21, no. 1, Article ID 04015006, 2016.

[34] Z. Fnag, F. Wang, Z. Zhang, C. Wang, and W. Ding, "Effects of viscous damper parameters on anti-seismic performance of long-span bridge," Journal of Highway and Transportation Research and Development, vol. 26, no. 2, pp. 73-78, 2009. 
[35] W.-P. Deng, H. Wang, A.-Q. Li, and J.-S. Liu, "Parametric analysis of viscous dampers for earthquake mitigation of continuous bridges in high intensity region," Zhendong yu Chongji/Journal of Vibration and Shock, vol. 31, no. 16, pp. 92-97, 2012.

[36] C. P. Providakis, "Effect of LRB isolators and supplemental viscous dampers on seismic isolated buildings under near-fault excitations," Engineering Structures, vol. 30, no. 5, pp. 1187-1198, 2008. 


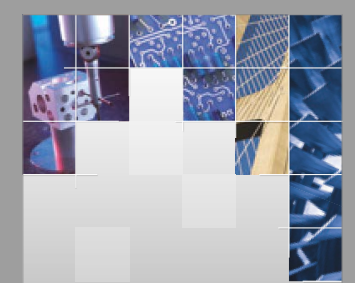

\section{Enfincering}
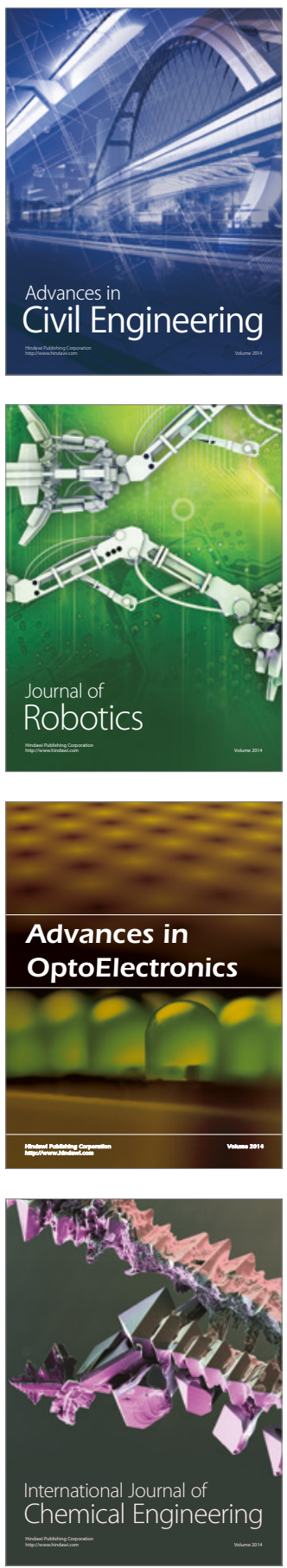

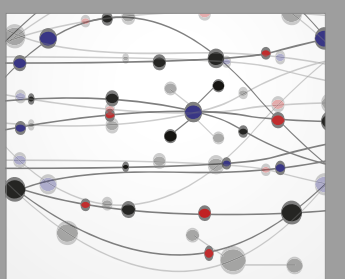

The Scientific World Journal

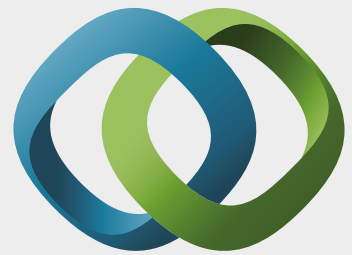

\section{Hindawi}

Submit your manuscripts at

https://www.hindawi.com
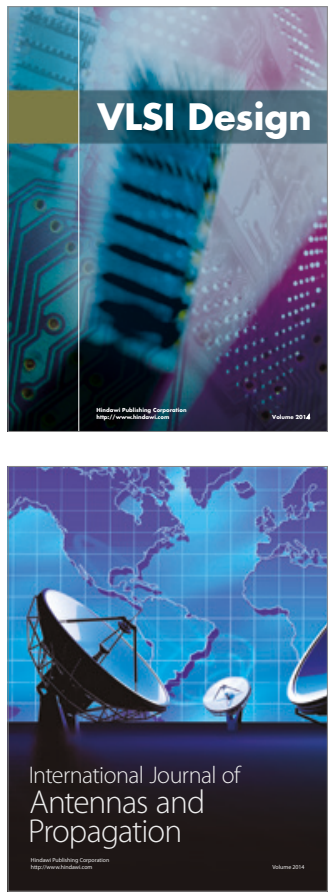

\section{Rotating}

Machinery
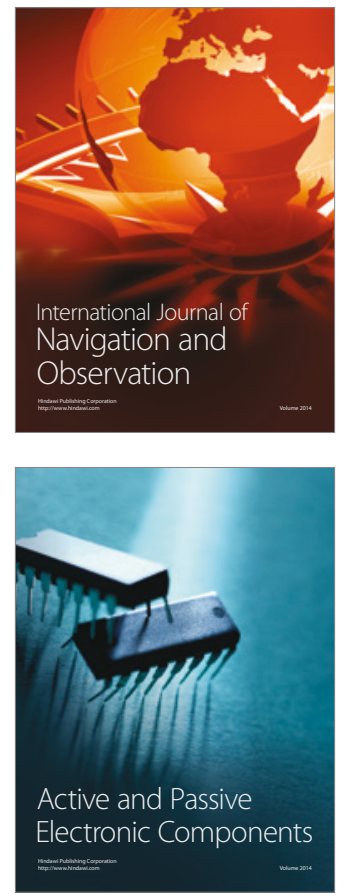
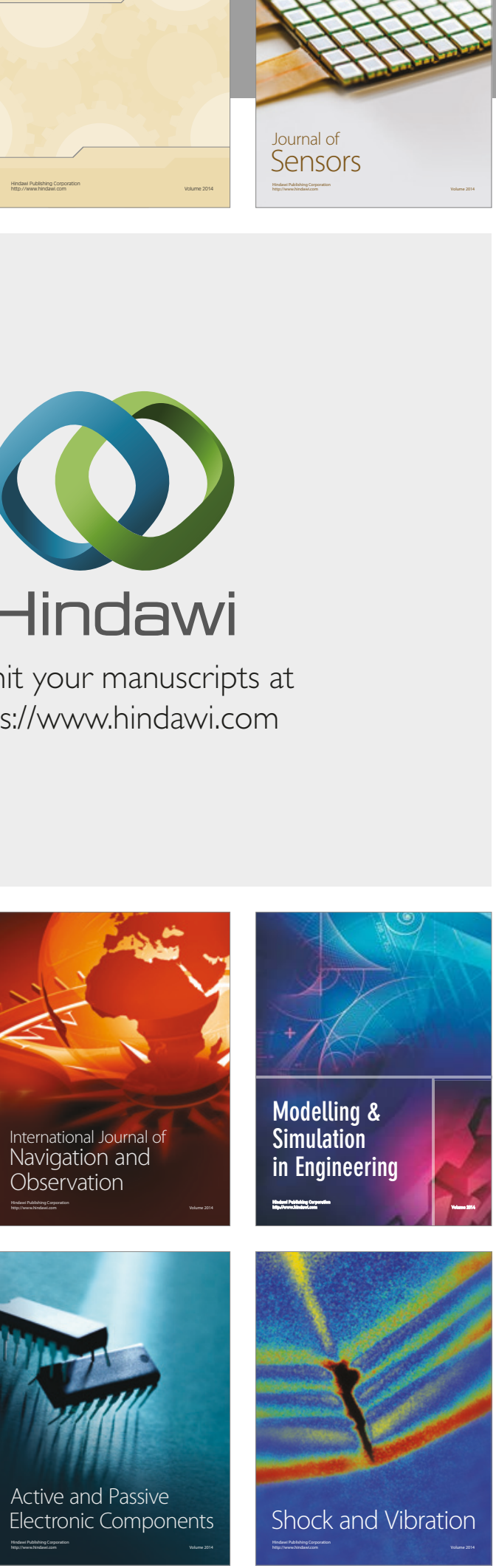
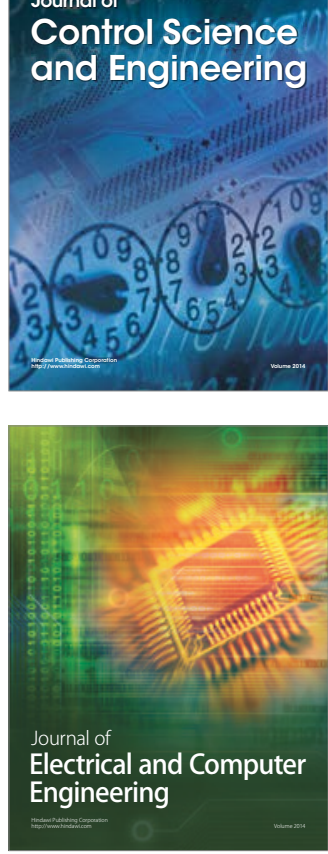

Distributed

Journal of

Control Science

and Engineering
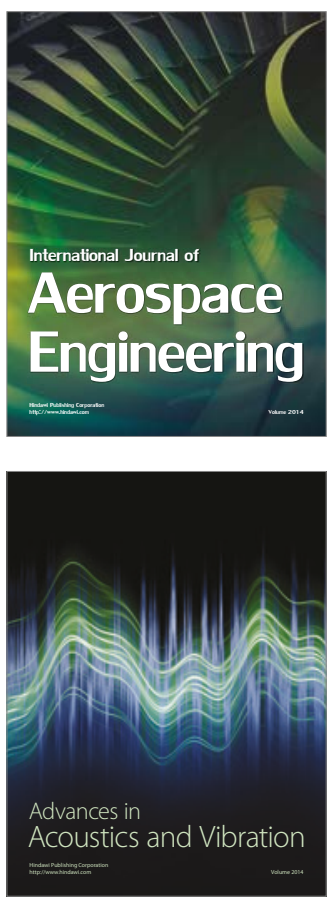

Sensor Networks 